\title{
Comparison of Housing Facility Management between Mainland China and Taiwan Region
}

\author{
Nannan Wang ${ }^{1}$; Yen-Chiang Chang ${ }^{2}$; Chao Zhang ${ }^{3}$; Haiyan Qin ${ }^{4}$; and Dongdong Jiang ${ }^{5}$
}

\begin{abstract}
Recently, mainland China has experienced the fastest urbanization in the world; however, the development of structural regulations regarding facility management (FM) services for housing is relatively recessive. As a result, disputes and conflicts in facility management of the private housing sector have become a serious problem in urban communities, affecting social sustainable development of the building industry. Comparatively, the private housing FM system in the urban areas in the Taiwan region was developed much earlier; thus, it is more advanced and mature than that in mainland China. This paper intends to compare the FM sectors between the two regions to provide suggestions for improving the service quality of the FM system in mainland China.
\end{abstract}

Author keywords: Facility management; Facility management fee; Facility management services; Built environment comparative analysis.

\section{Introduction}

Facility management (FM) for residential buildings is crucial to the living quality of habitants (Lai 2011). There is an increasing amount of research on FM sectors, such as customer satisfaction of FM (Hui and Zheng 2010; Ukoha and Beamish 1997) or quality surveys (Lai 2010). Before the economic reform in the 1980s, all social housing in the urban areas in China was completely owned by the state (Wang and Horner 2012). The rapid urbanization process in mainland China has created many private housing communities in the urban areas over the last 30 years. During this recent urbanization, the average housing floor area per capita in urban China increased from 6.7 to $27 \mathrm{~m}^{2}$ in nearly 30 years (National Bureau of Statistics of China 2009). With the improvement of living conditions, FM concerns have drawn significant attention from the public. Problems such as the low quality of FM services and FM providers' difficulties in collecting FM fees have caused extensive conflicts between owners and FM companies (Chen 2006; Hu et al. 2008; Zhang 2006, 2008). To address these problems in the FM sector, mainland China has issued special regulations to regulate relevant problems affecting FM services, such as FM regulation and special fund management measures for house maintenance. With the amendment of Facility Management Regulations (2007), China has made great improvements toward regulating the FM service market. For example, contracts between the

\footnotetext{
${ }^{1}$ Associate Professor, School of Management, Shandong Univ., Jinan, Shandong 250100, China. E-mail: southsouth@hotmail.co.uk

${ }^{2}$ Professor, School of Law, Shandong Univ., Jinan, Shandong 250100, China (corresponding author). E-mail: naluisle@aliyun.com; ycchang@ sdu.edu.cn

${ }^{3}$ School of Law, Shandong Univ., Shandong 250100, China. E-mail: chao.zhangsdu@gmail.com

${ }^{4}$ School of Management, Shandong Univ., Jinan, Shandong 250100, China. E-mail: chao.zhangsdu@gmail.com

${ }^{5}$ Graduate School of Technology Management, Univ. of Pretoria, Private bag X20 Hatfield, Pretoria 0028, South Africa.
}

residents and the FM service provider have been made formal. However, loopholes still exist. It is necessary to review and compare the FM service sector at both legal and operational levels in mainland China and identify areas for improvement.

\section{FM Sector in China}

The most common form of residential housing in mainland China comprises multistory and high-rise apartment buildings. Normally, the developer constructs a residential quarter involving many properties, which are sold to individual private purchasers. All facilities within the development are managed by an FM company/department. In recent years, there have been rapidly increasing numbers of conflicts between FM companies and the residential property owners, including dissatisfaction of the residents toward FM service quality and the difficulty faced by the FM company in collecting fees (Zhang 2008; Chen and Sun 2008). The FM market faces serious problems in development; for example: quality control, difficulty in collecting FM fees, and the usage of a special maintenance fund (Zhang 2008; Pan 2011). To ensure the sustainable development of the emerging FM market in mainland China, it is necessary to review the regulations and operation system of FM services.

Mainland China and the Taiwan region share similar institutional and cultural backgrounds. In comparison to mainland China, Taiwan started establishing its FM system much earlier. The first FM regulation in Taiwan was the Apartment and Mansion Management Regulation (1995). The current relevant regulations in Taiwan are more comprehensive and the FM market is much more mature (Fu 1999). Because most of the disputes in FM services in mainland China have related to residential apartments, this empirical research focused on reviewing and analyzing the regulations and operation of the FM services for residential housing properties in both regions.

\section{Research Methodologies}

The current research methods include a literature review and unstructured interview surveys. Ten experts in four facility management firms participated in the interview survey. To identify the areas of improvement that would be beneficial in the FM sector in mainland China, three aspects were selected to compare the 
facility services between the two regions: (1) FM fee, (2) management mechanism, and (3) quality assurance.

\section{Comparison of the FM Fees between Mainland China and Taiwan Region}

In both mainland China and Taiwan, the FM fees consist of two parts. In mainland China, this includes a special maintenance fund and facility service fee, whereas the FM fee in Taiwan region includes a public fund and FM service fee, as listed in Table 1.

In mainland China and Taiwan, the purposes of the public and special funds for house maintenance are similar. Both are collected from owners and retained for special purposes to be determined by the owners [Article 4 of Special Fund Management Measure of House Maintenance (2007); Item 3 of Article 18 of Apartment and Mansion Management Regulations (1995)]. Nevertheless, the application purviews are different in the two regions. In mainland China, the special fund for house maintenance can only be disbursed for "the major maintenance, renewal and restructuring of shared residential area and shared equipments after the warranty period" [Article 18 (Special Fund Management Measure of House Maintenance 2007)].

In comparison, the public fund in Taiwan region has wider application, and also covers the cost of management and maintenance of shared public areas [Article 11 of Apartment and Mansion Management Regulations (1995)]. First, this is because, on the mainland, the expenses of management and maintenance are included in a facility service fee. Second, the expenses of management and maintenance are regular expenses, whereas the special fund for house maintenance is collected only once at the outset of delivering the FM service in mainland China [Article 12 of Special Fund Management Measure of House Maintenance (2007)]. This item acts as a contingency fee for major repairs and the refurbishment of buildings, which may occur during the operation of the facilities. If management and maintenance were included in the scope of the application of the special fund for house maintenance, it would be difficult to calculate the amount of money to be collected at inception.

The FM service fee in Taiwan is similar to the facility service fee in mainland China: both are expenses to be paid to FM companies according to the FM service contract signed between the property developer or owners' committee (management committee) and FM companies. Both of the aforementioned fees are paid on a monthly basis; however, the fee calculating norms differ in the two regions. The facility service fee in mainland China follows the principle of autonomy of will in accordance with contract law [Item 2 of Article 35 of Facility Management Regulations (2007)]. Nonetheless, the calculation of some facility service fees is restricted by price standards and a floating range formulated by the relevant administration departments [Article 41 of Facility Management Regulations (2007); Articles 6 and 7 of the Facility Service Charging Management Means (2003)]. Therefore, the pricing of most FM service fees is guided by government regulations rather than the marketadjusted price, except for certain types of properties in mainland China. Nevertheless, in Taiwan, the charging of an FM service fee completely abides by the principle of "freedom of contract" in accordance with the civil code, which is determined by management companies and established owners in FM contracts.

This difference between the two regions, in terms of pricing the FM services, relates to the maturity of the relative FM markets and the degrees of the property owners' involvement in FM. On the mainland, therefore, where the facility service industry is less mature and owner involvement is very limited, the government guided price seems more appropriate at present. When the private housing market started to emerge in China in the 1990s, owners' low awareness of involvement in FM resulted in the failure to establish owners' committees. It was found during the interview survey that for most cases in which an owner's is committee established, the committee often fails to work effectively in practice. Generally, the developer employs its own FM department to manage the properties. In this way, the developer determined how to charge the FM fee according to the service content, which they provide unilaterally. One of the interviewees pointed out that "the FM service market in Taiwan region was more regulated and clearer than the current FM service market in mainland China." The price are occasionally against the owners' will, leading to contradictions between owners and FM companies, because there is no consensus mechanism established between the two parties. Thus, the government in mainland China issued guiding standards for FM service charges for the purpose of avoiding disputes between the developer and the property owners (Li 2005).

With further development of the FM service market and increasing awareness of owner involvement in recent years, the inflexible government guidance has hindered market adjustment on FM fees. The time now appears propitious for FM services to adopt marketbased prices, so that property owners are free to choose satisfactory FM companies according to service content and standards. Competition among FM companies may also promote improving service quality and reduced costs, to achieve a greater market share. The problems regarding FM fees can be classified into two categories: fee collection and fee usage, which are analyzed in the following.

\section{Collection of FM Fees}

\section{FM Fee Payers}

In accordance with Article 42 of Facility Management Regulations (2007) and Article 15 and Article 16 of Facility Service Charging Management in Mainland China, the payers of FM fees are primarily property owners and developers. The developer pays the FM fee before handing over the properties to the purchasers. After the property transferral stage, the responsibility for the payment is transferred to the owners. Because the property owners hold the properties for a much longer period, they are the primary payers of facility service fees. In addition, there are strict requirements for the owners to pay the FM fees; for example, the defined liability and penalty for owners failing to pay the fees.

There is no strict requirement for the tenants to pay fees in mainland China. In Taiwan, the fee payers can be the owners and occupiers (for example, tenants), as defined by Article 21 of Apartment and Mansion Management Regulations (1995). For example, the cost of reactive maintenance work, if caused by the tenant, would

Table 1. Comparison of the FM Fees in Mainland China and Taiwan

\begin{tabular}{lccc}
\hline Mainland China & Taiwan & Purpose & Payment method \\
\hline $\begin{array}{l}\text { Special maintenance fund } \\
\text { Facility service fee }\end{array}$ & Public fund & Maintenance and repair of facilities & One transaction for whole project \\
\hline
\end{tabular}


be paid by the tenant [Article 8 (Apartment and Mansion Management Regulations 1995)] rather than the owner.

In compliance with Article 6 of Special Fund Management Measure of House Maintenance (2007), in mainland China, owners are the primary payers of the special house maintenance fund and their liability for payment is compulsory by law. The situation differs in Taiwan, where the owners and the developer are liable to pay the public fund, which is compulsory. According to Article 18 of Apartment and Mansion Management Regulations (1995), the developer has to contribute an amount, namely a certain percentage of construction costs, to the public fund. The owners' liability to pay the public fund is determined by the owners' committee. Thus, the majority of the public fund in Taiwan is paid by the developer, not the owners.

At first glance, the payers of the fees are significantly different between mainland China and Taiwan. However, the interview survey revealed a unique practice in mainland China. All of the interviewees suggested that the payers of the fees in mainland China were actually the property owners. This is because the developer normally includes the fund in the property price when the owners purchase the properties. Thus, the owners have paid the developer's cost for the construction and maintenance of buildings, even before the properties have been transferred to them.

\section{Difficulty in Collecting FM Fees}

The difficulty in collecting FM fees has always been the most significant and difficult problem to solve in the FM sector in mainland China (Chen 2006; Zhang 2008), and has become a common and difficult problem in the FM service industry. Because the owners' liability to pay the special house maintenance fund is a compulsory requirement for the owner's certificate of title, there is no difficulty in collecting special fund payments. It is the collection of the facility service fee that poses problems.

There are several reasons for this phenomenon. First, the liability to pay the facility service fee represents a bounded responsibility of multiple users, rather than an individual agreement between the FM companies and each owner (Li 2005). This differs from other forms of purchase in that the FM service is provided by an FM company to a diverse group of customers, namely the entire gamut of property owners. Second, the FM companies cannot terminate their services owing to an individual owner's refusal or delay of payment (Zhang 2008). In fact, the individual owners would still receive services even if they failed to pay the facility service fees. Many property owners are not used to paying for FM services because such services were delivered by the public sector without charge (Wang and Horner 2012), prior to housing privatization in the 1990s. Thus, owners require time to accept that they now have to pay for something that used to be free (Wang 2008; Chen 2006). In addition, most FM companies evolved from former state-owned institutions, which lacked a sense of market competition. Thus, their performance in terms of efficiency and service quality was unsatisfactory, but they were entitled by national regulation to charge the standard fees. This has resulted in the reluctance of owners to pay for poor services, and such sentiments are growing (Zhang 2008; Hu et al. 2008).

Customer awareness in Taiwan is different from that in mainland China in that they have acknowledged the relationship between the price and quality of a service. The private housing market in Taiwan has developed over a long period, with the result that Taiwan's facility service industry is more mature than the market in mainland China and, after years of development, its market mechanism is robust.
On the mainland, there are relevant measures to encourage owners and property users to pay for an FM service; for example, the FM companies are entitled to bring a suit before the people's court [Article 67 (Facility Management Regulations 2007)]. However, this measure has little effect in practice because the litigation cost is far greater than the FM fees. In the Taiwan region, the FM companies can also bring a suit before a court, according to Article 21 of the Apartment and Mansion Management Regulations (1995). Furthermore, it states in Article 22 that under some conditions, the company may conduct a compulsory eviction of those residents who continuously fail to pay the FM fee. That is to say, the FM management committee can, after agreement with the nominated owners' committee, bring a suit before the court to force those owners "who again failed to pay for service fee exceeding $1 \%$ of the of distinguished ownership price, to vacate the property." This act has significant effects and renders severe punishment to those who refuse to pay FM fees.

This experience in Taiwan may be of valuable reference for the FM market in mainland China; however, there lacks legal support to enforce the same punishment on the owners. According to Article 83 of Property Law of the PRC (2007), the property owners' committees are not entitled to appeal. This concern arises primarily because such organizations do not own private property; thus, are unable to independently accept civil liability (Huang 2007). Because of the reluctance of the owners to become involved in FM and limited rights, the owners' committee is difficult to establish, let alone to make decisions on behalf of the owners. Moreover, compulsory eviction is essentially a right to request on the matter, which aims to protect the owners rather than the FM providers (Pan 2011). As a result, the FM companies have no right to appeal when experiencing compulsory eviction. Mainland China can learn from Taiwan's experience to introduce punitive measures to the debtors, such as high fines and publicizing the names of residents who fail to pay FM fees.

\section{Usage of the FM Fee}

\section{Usage of the FM Fee in Mainland China}

The usage procedures of the special maintenance and public funds are different in mainland China and Taiwan regions.

The usage procedure of the special maintenance fund on the mainland varies with individual management bodies. Before the establishment of the owners' committee, the special maintenance fund is controlled by a governmental asset management department [Article 10 and Article 11 of Special Fund Management Measure of House Maintenance (2007)]. Once an owners' committee is established, they will take charge of the fund management [Article 15 of Special Fund Management Measure of House Maintenance (2007)].

Article 22 of the Special Fund Management Measure of House Maintenance (2007) relates to the usage procedure of the special maintenance fund before the owners' committee takes over the management role of the fund. This procedure is complex:

1. The FM company or owners propose suggestions for fund usage;

2. Usage is approved by a certain number of owners, though discussion;

3. Works are conducted according to plan;

4. FM companies or owners report a detailed expense list to the governmental asset management department;

5. The governmental facility management department issues approval and notice of bank transfers; and 
6. Bank transfers capital to the contractor who delivers the maintenance works.

During this procedure, there is a lack of restrictions on the timeline of the official approvals, which results in low efficiency when using the special maintenance fund and delays in building maintenance works. It has been claimed that the usage rate of the special maintenance fund in Beijing is only 3\% (Wang 2011).

In the later stages, when the owners' committee takes over the management of the special maintenance fund, the withdrawal of the fund follows a different procedure from the previous stage [Article 23 of Special Fund Management Measure of House Maintenance (2007)]. The procedure is as follows:

1. The FM company proposes a plan of fund usage;

2. The owners' committee approves the plan;

3. FM company executes according to the plan;

4. The FM company reports its expenses list;

5. The owners' committee provides approval;

6. Notice is given to the bank to transfer funds; and

7. The bank transfers the funds to the FM company.

The usage of the special maintenance fund does not require the approval of the governmental asset management department, which is only requested to archive the related documents. However, it is also stated in the special fund management measure of housing maintenance that the governmental asset management department may order the two parties to rectify any actions contradictory to government laws and regulations. The result is that the governmental asset management department has responsibilities in not only achieving but also in supervision.

Above all, the procedure for using the special maintenance fund in mainland China is complex and time-consuming, resulting in low usage of the fund. Another concern is the late start of the housing market in mainland China. The current apartment buildings in mainland China were built relatively recently; thus, it will take some time before major maintenance works are necessary.

\section{Usage of the FM Fee in Taiwan Region}

In Taiwan, the fund usage procedure is much simpler because it does not need to be approved or filed by the governmental management department. The public fund in Taiwan region shall "be decided by distinguished owners' committee," according to Item 3 of Article 18 of Apartment and Mansion Management Regulations (1995). The fully autonomous procedure of fund usage is built upon the basis of high involvement and awareness of the identified owners in Taiwan.

\section{Comparative Assessment}

However, the management of the special maintenance fund is commonly controlled by the asset management department owing to the failure to establish an owners' committee in mainland China. The usage of the special fund takes much longer owing to the requirement of official approval in mainland China, as opposed to in Taiwan. When the owners' committee is successfully established, the procedure to transfer special maintenance funds from the governmental asset management department to the committee is very complex (Wang 2011). In the interview survey, an FM company stated that the department overly focuses on checking the usage of special maintenance funds, with the result that the supervision step normally requires a considerable period. Indeed, the current usage procedure has affected the performance and the capital management of FM companies in China because the usage of the FM fee has to pass a time-consuming assessment process.
As a result, to improve the efficiency of fund usage, it is suggested that the mainland establish a time limit for departmental approval and supervision steps for both policy and mechanism. In addition, it should simplify the procedure of transferring special maintenance funds to the owners' committee. After the transfer, the department should reduce their involvement in fund control and grant more rights to the owners' committee.

\section{Comparison of the FM Operation Mechanism between Mainland China and Taiwan Region}

Currently, in mainland China, the FM mechanism for residential property utilizes an FM company. However, there is another route in Taiwan; namely, self-FM by property owners (Liang and Gao 2003). In this process, the owners maintain and manage the facilities in the residential community without appointing an FM company (Fu 1999). The primary advantage to this mechanism is the low cost in managing the facilities. Under this mechanism, the owners select a management committee responsible for FM management. The committee normally includes a full-time manager and controller and several part-time workers. The result is that the labor costs relating to FM can be substantially reduced in comparison to the management mechanism operated by a private FM company. This mechanism seems ideal in addressing the complicity between the FM companies and the owners in mainland China; however, there are some constraints to this successful implementation of this system in mainland China.

The success of self-FM requires high awareness of involvement and FM knowledge on the part of the owners, which is currently lacking in mainland China. This is because society in mainland China institutionally lacks citizen autonomy (Chen and Sun 2008). The other reason is that residents in the same multioccupied property in mainland China habitually have little contact with each other. There is a general lack of trust and sense of belonging among the owners; consequently, it is difficult for them to consider the common benefits of a whole community and become involved in FM.

Although the self-FM mechanism seems a good choice for low to medium income house holders, it is difficult to widely apply in mainland China without improvements to owners' involvement in FM. Researchers have suggested that the government should issue guidance and regulations regarding self-FM in mainland China to meet the demands of the majority of residents (Chen and Sun 2008).

\section{Comparison of FM Quality Assurance between Mainland China and Taiwan Region}

Government intervention in quality assurance on FM services exists in both mainland China and the Taiwan region. In Taiwan, FM service is regulated by insisting upon relevant qualifications for FM companies and management service personnel. The FM professionals for residential accommodation are classified into three categories subject to different requirements, including: routine management, fire safety facilities management, and equipment safety management personnel. The classification of FM professionals can promote professional levels of service and improve the quality of FM operations.

In mainland China, FM service quality is ensured by establishing the standards of the management system of an FM company, providing an FM personnel qualification certification system, and establishing criteria guiding the FM service. The professional qualification regarding FM is not as strict as in Taiwan, because 
there is only one general certificate for FM personnel in mainland China. Thus, there is a lack of specialization regarding FM services and a clear division of FM operations in mainland China. It is necessary to classify FM professionals in accordance with various FM duties. In addition, the establishment of a performance assessment system for different FM professionals would also improve the service quality of FM in mainland China.

\section{Conclusions and Recommendations}

This paper compared the differences in residential FM sectors between mainland China and Taiwan region from legal and operational aspects. To improve the social sustainable development of China's building industry, there are many aspects of provenance that may be learned from the experience of the FM sector in Taiwan. The majority of owners do not have a clear understanding of their roles and positions in FM services, causing low involvement in FM. The recommendations for practitioners in FM in mainland China are as follows:

1. The government should simplify the approval and supervision procedure regarding the special maintenance fund, and lead the FM sector to develop toward a more market-driven direction.

2. The Chinese government should introduce legislation regarding appropriate punishment mechanisms for residents not paying FM fees.

3. The introduction of self-FM in Taiwan to the urban communities in Mainland China may take some time. Meanwhile, the government should taking action to promote owners' involvement in FM operations.

4. A professional certification system should be introduced to the FM sector in mainland China to increase the necessary degree of specialization and quality assurance of FM services.

5. The government should establish some pilot programs, starting with some areas in which there is already a strong sense of community and willingness to be involved in FM.

\section{Acknowledgments}

This research is sponsored by: Natural Science Foundation of Shandong (Grant No. ZR2013GQ014); Independent Innovation Foundation of Shandong University (Grant No. IFW12108; IFW12065).

\section{References}

Apartment and Mansion Management Regulations. (1995). "Presidential office." Presidential Order No.: 4316, Taipei, Taiwan.

Chen, J., and Sun, J. (2008). "The pro and con of applying self-operated facility management in old residential community." China Facil. Manage., 1, 28-29 (in Chinese).
Chen, S. (2006). "Initial analysis: The fact of difficulty in collecting facility management fees." China Electricity Education, Beijing, China (in Chinese).

Facility Management Regulations. (2007). "State council of PRC." Order No. 504, The State Council of PRC, Beijing, China.

Facility Service Charging Management Means. (2003). "The national development and reform commission of PRC and the ministry of construction of PRC." Order No. 1864.

$\mathrm{Fu}, \mathrm{C}$. (1999). "Introduction of self-operated facility management system in Taiwan." China Real Estate, 10, 279 (in Chinese).

$\mathrm{Hu}$, X., Wang, F., and Cheng, X. (2008). "Game theory analysis on difficulty in collecting facility management fees." Modern Finance, 7(1), 105-114 (in Chinese).

Huang, S. (2007). Explanation and implication of the property law of the People's Republic of China, People's Court Press, Beijing, China.

Hui, E. C. M., and Zheng, X. (2010). "Measuring customer satisfaction of FM service in housing sector: A structural equation model approach." Facilities, 28(5-6), 306-320.

Lai, J. H. K. (2010). "Investigating the quality of FM services in residential buildings." Proc., W070-Special Track, 18th CIBWorld Building Congress, International Council for Building, Rotterdam, The Netherlands, 13-25.

Lai, J. H. K. (2011). "Comparative evaluation of facility management services for housing estates." Habitat Int., 35(2), 391-397.

Li, Y. (2005). "The study on the legal issues in facility management." $\mathrm{Ph} . \mathrm{D}$. thesis, China Zhengfa Univ., Beijing, China (in Chinese).

Liang, J., and Gao, P. (2003). "Property management to achieve a two-track system in line with national conditions." China Lawyer, 5, 70-71 (in Chinese).

National Bureau of Statistics of China. (2009). "Living standard of citizens." Central People's Government of the People's Republic of China, 〈http://www.gov.cn〉 (Oct. 11, 2013) (in Chinese).

Pan, L. (2011). "A legislation study of the condominium ownership mandatory deprivation issue." People's Court in Kaifeng Network, 〈http:// fayuan.kaiping.gov.cn/article.asp?id=1511) (Oct. 11, 2013).

Property Law of the PRC. (2007). "The state council of PRC." Order No. 504, Beijing, China.

Special Fund Management Measure of House Maintenance. (2007). "Ministry of construction of the PRC and Ministry of Finance of the PRC." Order No. 165, Ministry of construction of the PRC and Ministry of Finance of the PRC, Beijing, China.

Ukoha, O., and Beamish, J. O. (1997). "Assessment of residents' satisfaction with public housing in Abuja, Nigeria." Habitat Int., 21(4), 445-460.

Wang, D. (2008). "Study on difficulty in collecting facility management fees." Economist, 7 (in Chinese).

Wang, E. (2011). "Only 3\% usage on the 13billion commercial residential special maintenance funds." 〈http://finance.qq.com/a/20071031/002708 .htm) (Oct. 11, 2013).

Wang, N., and Horner, M. (2012). "Is privatization the answer for social housing?" Comp. Study China U.K., Housing Soc., 39(1), 99-124.

Zhang, H. (2006). "Reconsidering the problem in collecting facility management fees." Univ. Time, 10 (in Chinese).

Zhang, J. (2008). "A shallow discussion on the difficulty in collecting facility management fees." China Technol. Inf., 23, 154-155. (in Chinese). 